\title{
Exploration on Time Feature Evolution of China's “Oceanid" Matsu Statue
}

\author{
Haiyan $\mathrm{He}$ \\ School of Arts \\ Xiamen University \\ Xiamen, China
}

\begin{abstract}
This paper aims to have a deep analysis on China's "Oceanid" Matsu statue and elaborate its time feature evolution in the following aspects: Start with analysis on Matsu statue, introduce time feature changes of its image from an ordinary girl to a madam, concubine and honorable imperial concubine of the heaven of upper class, and introduce diversified development formed by supreme queen of the heaven image and modern $Q$ version Matsu image.
\end{abstract}

Keywords—Matsu; times; feature

\section{INTRODUCTION}

Matsu is also called imperial concubine of the heaven or queen of the heaven. In folk, she is called mother in southern China and empress in northern China. She is also called Lin Mo or Mother Mo when she is still alive. According to legend, she was born in Lin family, ancient Xianliang Port (Gangli village at present), Putian, Fujian province on lunar March 23, 960 A.D. Since she never cries from birth to one month, her parents call her Lin Mo. She "goes up to heaven" on lunar September 9, 987 A.D. She dies at the age of only 28. During her short life, Lin Mo "gets a sign when she is looking towards a well, from then on she is well informed of changes, drives out evils, conducts salvation, shows miraculous behaviors and often rides clouds to go across ocean." Therefore, she is loved by local people very much. "There are populace, sub-lineage and fellow villagers building a temple titled "Competent Talent" for her when she is still alive. Due to her multiple "presence" to drive out drought, drive out plague with holy stream, save merchant ship out of water crisis or assist the court in fighting against bandit in emergency disaster moment. She is not only worshiped by folk citizens, but also gets promoted in godhood by imperial court for several times. Therefore, since Song Dynasty, worshipers of Matsu can be fisherman, boatman, sailor, merchant, politician and official; They can come from southeast coastal region, south and inland of China; They can come from mainland, Taiwan, Hong Kong and Macao; They can be domestic and foreign. "There are almost ten thousand Matsu temples all over the world and there are over 0.2 billion believers from 33 countries."

With propagation range and influence power of Matsu getting greater, the original "Oceanid" Matsu mainly in charge of ocean protection transforms into an omnipotent versatile goddess granting whatever is requested. Especially in 1980s, Matsu is honored the title of "peace goddess" by the United
Nations; On September 30, 2009, "Matsu belief" wins the first honorable title of "world belief intangible culture" in China. Matsu worship gets promoted into a kind of cultural phenomenon from a folk and local belief. Among them, as medium of people's spiritual or material activity, Matsu statue is the necessary result of Matsu belief and an important carrier of Matsu culture.

\section{CURRENT DeVEloping Situation of Chinese MATSU'S GODHOOD IMAGE}

In recent years, there are many scholars paying close attention to development trend of Matsu's godhood image and Matsu statue. Its cultural image attracts great attention in academic circle. Teacher Wang Yingying from Fujian Normal University discusses Matsu statue concept, artistic carving of Matsu statue, graphical modeling and other aspects under modern cultural concept in details. But further discussion is needed as to Matsu's personal image and development and evolution of Matsu's godhood image. Mr. Tang Hongjie conducts analysis from the perspective of Matsu statue cultural relic appreciation of previous generations. However, there are limitations. Firstly, left Matsu statue cultural relics of previous generations are mainly from the folk and renovation and modification by believers arouse argument as to this kind of cultural relic's division of history; Secondly, there is little description of personal and godhood image of Matsu, especially facial features in relevant biography and legend material, and there is no description about her five sense organs, skin color and height.

Of course, from the perspective of Chinese traditional culture, it conforms to reservation and simplicity promoted in Chinese national traditional spirit and leaves space for people to imagine. Seeing from another perspective, due to entitlement of imperial court, godhood image of Matsu becomes a kind and dignified queen of heaven from a simple commoner gradually. What's more, people's aesthetic concept changes with subject. Due to influence of times, region and so on, different craftsmen's creation and manifestation of Matsu statue contain the trace of times, region, culture, politics, economy and so on. Therefore, there are great differences between various Matsu temples and Matsu statue images worshiped by people at home. Good and bad artistic carvings are intermingled. So, image of Matsu is more complicated and confusing and it is necessary to do up material concerning 
personal image and godhood image of Matsu in details and find out revolution and developing venation of Matsu image and statue as a reference for current various image design of Matsu.

\section{ANALYSIS ON IMAGE CHARACTERISTICS IN MATSU LEGEND}

Due to chances of visiting, learning, designing and researching, the author gets to know and collects relevant description of personal image of Matsu in Matsu Legend as follows: "A red light appears and it is so brilliant and eyecatching. Exotic fragrance is too thick to disperse. She never cries from birth to a month old. She is smart as a young child. At the age of 8 , she learns to read from tutor in old-typed private school and can understand meaning of articles. At the age of more than 10, she likes to burn incense on tea table, chant sutras and pay respect for buddha. She never relaxes in morning or at night. A graceful young girl has gentle gestures. At the age of 13, she likes to give in charity. At the age of 16, she looks into a well and gets a sign. From then on, she is wellinformed of changes, drives out evil, conducts salvation, constantly shows magic and often rides clouds to cross the sea." Since there is no more detailed personal image description of Matsu in Legend, we can only look on her far away. Like looking at flowers in fog, we catch a glimpse of a fine-looking young female with great destiny who is smart and likes to learn as a young child, and likes to burn incense and pay respect for buddha. She is different from ordinary girls in being uniquely smart, elegant and powerful. She is easy-going and philanthropic, just like the girl next door. Besides, she is innocent and loves beauty like all adolescent girls. She and her companions "look towards the well" in a quiet and peaceful courtyard to watch their own appearance. However, she is entitled with a sign by a holy man at the age of 16 . From then on, she can do spirit speaking and do salvation. Description of image of Matsu before her death is full of youth and healthy vitality. However, it is very difficult to find personal image god statue or sculpture of Matsu of this period among relevant cultural relic of Matsu image kept all over the world.

\section{Chinese Matsu STATUE'S TIME FEATURE EVOLUTION}

\section{A. The Image of A Plain and Ordinary Girl}

"Weaving in the rear, closing eyes and her look changing instantly. Holding shuttle in her hands and stepping on boss rod with her feet ...", "Later on, people can see her picking and encounter her every ten days. I mistakenly regard her as an ordinary girl ...", "One day, when she walks alone on mountain road, Jiaying regards her as an ordinary beautiful girl and intends to offend her ...", "They thrust against the ground to help her, seeing small rocks and a girl collecting periwinkle ..." Among all myths and legends of Matsu, relevant description of her is the image of a weaving peasant girl, plucking labor girl in folk, folk beauty walking alone on mountain road and folk girl collecting periwinkle. In this period, godhood identity of Matsu is still a folk goddess. Although these various folk girl images recorded in legend are untraceable in time and possibly don't exist: This kind of various images of fantastic transformations of Matsu can appear in Song Dynasty when Matsu lives and can also appear in Ming Dynasty, Yuan Dynasty, Qing Dynasty and so on. Scheler says "People describe themselves on god". People place their understanding of and yearn for beauty on imagination of the image of god.

Therefore, in theory, creation of Matsu is peasant girl image of various periods and various regions. However, according to description in The Age of Matsu (960 AD - 976 AD) and a Chinese mythology, Matsu stays among plucking women and conquers monster Jiaying. The author prefers peasant girl image of Matsu as the Song female image. Nowadays, there is little material concerning Matsu picture or statue as peasant girl image. But many worshiped Matsu statues in temporal palaces of Putian, Fujian are young. Some images have young, delicate and beautiful faces, five pretty and exquisite sense organs, powdered faces and female eyebrows, elegant and dignified, just like "Fig.1"; Some images have solid and clear-cut faces, high cheekbones, thick lips, big eyes and bushy eyebrows. They are local peasant girl images, just like "Fig.2". These statues clearly manifest local people's aesthetic consciousness of Matsu's kind and tender feelings in plain folk. For the time being, we take them as reflection of Matsu's folk girl image.

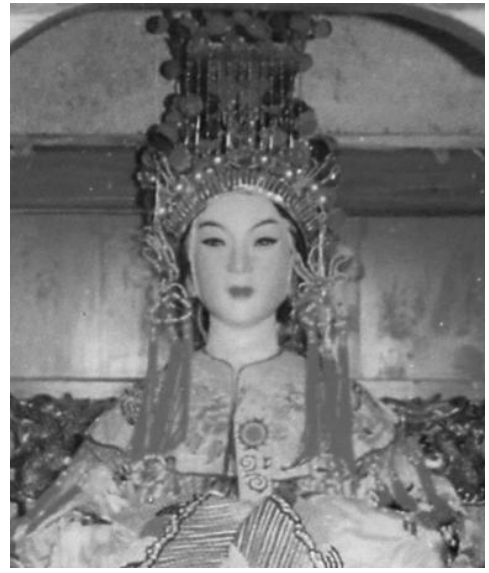

Fig. 1. Matsu of the temple of heaven in Huadong Village, Huangshi, Putian in Wang Yingying's Artistic Analysis on Putian Matsu Statue Carving

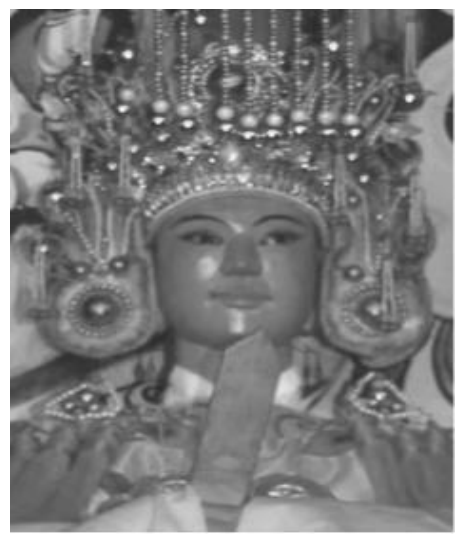

Fig. 2. Matsu statue of Mingshan Palace in Jiaoxi, Huating, Putian in Wang Yingying's Analysis on Statue Concept of Matsu Image in Fujian and Taiwan in Modern Cultural Construction 


\section{B. Madam and Imperial Concubine Image of Upper Society}

"Seeing a goddess sitting up on mast in vermilion clothes." The description is about her rescuing and sitting up in vermilion clothes. Matsu of this period is honored the title of "Shunji" by Emperor Huizong of Song Dynasty, tax revenue of sacrifice field is reduced and temples are built in Three River Port for sacrifice; "Faintly seeing a goddess in clouds with brilliant cover and flying banner, just like lightning and rainbow.'The description is about Matsu sitting on clouds and gorgeous head cover of carriage ridden by Matsu. It is a dignified and mysterious image, like accompanied by lightning and rainbow. Matsu of this period is honored the title of "Welfare madam of kind spirit displaying and advocating goodness" by Emperor Xiaozong of Song. Godhood identity of Matsu has been promoted to "madam" with social status from folk goddess; "The saying has not stopped. Suddenly, rain clouds cover the mist and people faintly see a woman in bright red clothes crowded by gorgeous motorcade. The description is about Matsu in red clothes and crowded by gorgeous motorcade with crystal and dazzling brilliance like rainbow shining. In the first year of Emperor Guangzong of Song Shaoxi period (1190 AD), due to "great merit of driving out drought", Matsu is honored with praise and promoted to a higher office of "Concubine Linghui" and her godhood is promoted to "imperial concubine" from "madam".

These legends about Matsu saving the world mention "red clothes" and "banner". Although they have no detailed description of Matsu's personal image, according to "Regulation in Zhenghe years of Emperor Huizong of Song: 'It orders that women's headgear is flower hairpin crown with the hair style of two sided hair temples in jewelry decorated di clothes'. 'Women's casual clothing should be red with super sleeves. Take red pattern woven fabric as collar, and red woven fabric long dress, red cape and jade as pendant. They should wear red woven fabric stack, yellow and red yarn undershirt, white yarn fork pants, yellow dress, and pink yarn blouse" ". "Fig.3"; According to recording in Song History. Official Garment Record: costume of the queen and maids of honor of different rank: The first is ceremonial dress, the second is red garment and the third is ceremony garment. Their hair is lined with fake hair knot and decorated with high crown and various kinds of jewelry. The crown can also be decorated with nine pheasants and four phoenixes in the hair style of two sided hair knot." Formal dress of the queen and maids of honor of different rank in Song Dynasty is also called "red dress". Therefore, image of Matsu in legend of this period often comes with gorgeous red dress and banner.

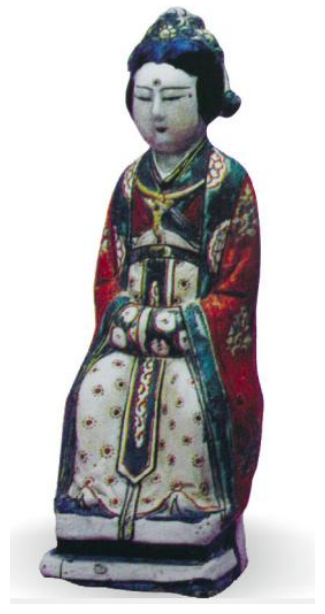

Fig. 3. The portrait of a lady in Song Dynasty in Tang Hongiie's Appreciation of Matsu Statue of Past Dynasties

As to currently existed Matsu statues of Southern Song Dynasty, like Matsu statue of Wenfeng Palace in urban area of Putian in "Fig.4" and Southern Song Dynasty madam Matsu statue of Lingying Hall in Haibin Village, Fengting, Xianyou in "Fig.5", their hair style conforms to Song History . Wuxingzhi: "In Lizong period, concubines have high hair knot at the top of head, which is called 'Never walking down'." Matsu in statue has high hair knot at the top of head. Her elegant and dignified presence and hand hiding type sitting posture are presence model of concubines and ladies of that period. These two Matsu statue cultural relics are material object proof of Matsu as madam of upper society in Song Dynasty; In Xianliang Harbor Song Dynasty Matsu Statue in Different Makeup of "Fig.6", distance between eye and brow is much wider than that in other statues; This statue has phoenix eyes, arch eyebrows, a delicate high nose, a small cherrylike mouth and sight giving out some majesty. It is material object proof of Matsu's concubine image of Song Dynasty. In addition, age features of madam and concubine Matsu statues conform to identity. Obviously, they are much older than the peasant girl image of Matsu.

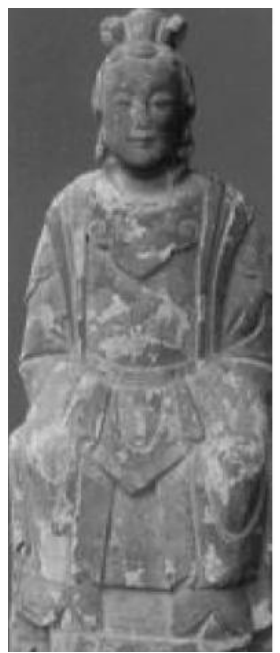

Fig. 4. Matsu statue in Wenfeng Palace in Wang Yingying's Analysis on Artistry of Putian Matsu Statue Sculpture 


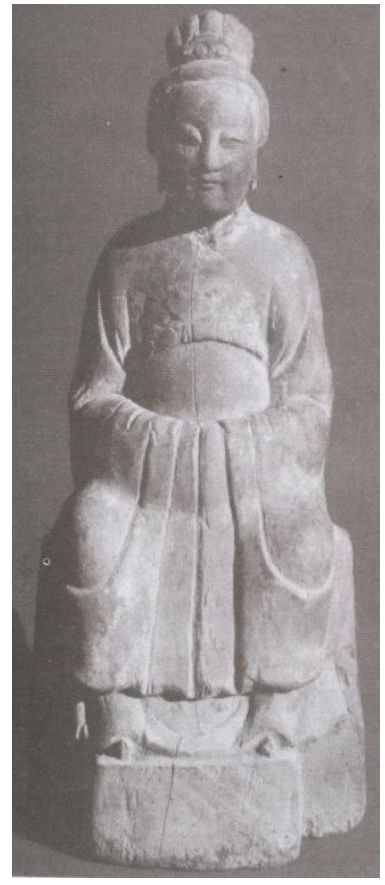

Fig. 5. P347 of Outline of Matsu Study, with Huang Ruiguo as editor-inchief

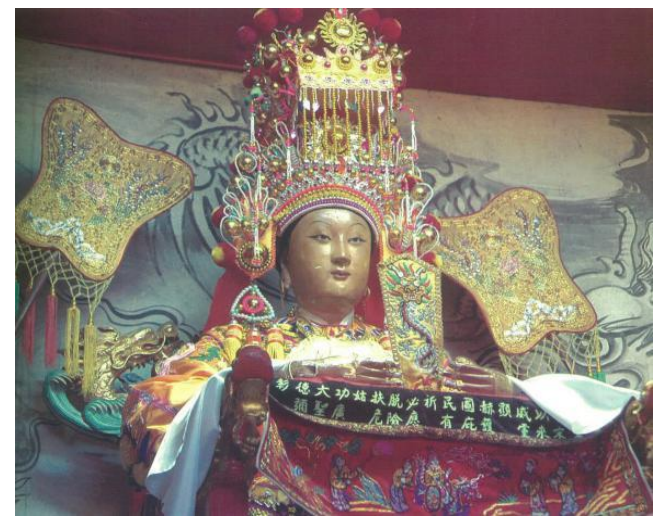

Fig. 6. Color drawing on Page 1: Matsu statue with different makeup of Song Dynasty in Xianliang Harbor in Lin Qingbiao's Legend of Entitlement of the Queen of Heaven in Qing Dynasty

\section{Honorable Imperial Concubine of the Heaven Image}

Governors of Yuan Dynasty attach great importance to sea transportation and Matsu is the goddess managing blessing on the sea. Due to her great service in "protecting Caoyun system", Emperor Yuanshizu honors Matsu as "Outstanding concubine protecting the country" in 1281 AD. Matsu's godhood status gets promoted to queen of heaven related to development of the country from concubine. As to costume of Yuan Dynasty, there is Mongolian style in "Fig.7": "Garment of emperors of Yuan Dynasty is mainly Mongolian made Zhisun Mongolian costume with warm kam hat on head and should knot (Jiaha in Mongolian) sometimes." Although there is little description of personal image of Matsu in legend of this period, in currently existed Yuan Dynasty Queen of Heaven Garment Matsu Statue in "Fig.8", she wears a warm hat on head and wears Jiaha on shoulders. Matsu is born in south, but she wears Mongolian costume. Obviously, it is influenced by times, region and governor's aesthetic preference. In legend of Matsu, there is little description of personal image of Matsu as queen of heaven in Ming Dynasty. However, in Ming Dynasty Moralization Porcelain Carving Matsu of "Fig.9", she wears a crown on head and wears Jiaha on shoulders, sitting up with one hand in the other before her chest. As you see, Matsu image of this period still contains some legacy of Yuan Dynasty.

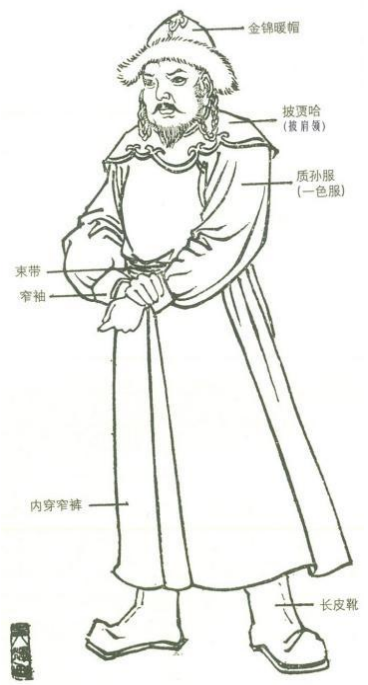

Fig. 7. Zhisun Mongolian clothes drawn by author on Page 216 in Huang Hui's Uniform Types of Past Generations in China

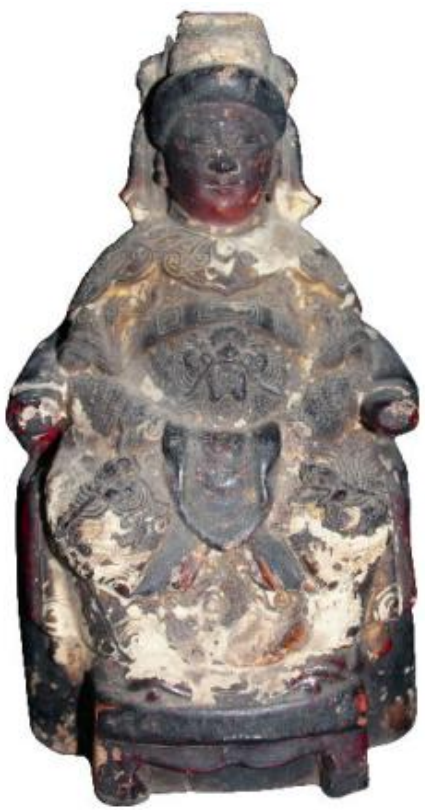

Fig. 8. Matsu statue in concubine clothes in Tang Hongjie's Appreciation of Matsu Statue of Past Generations 


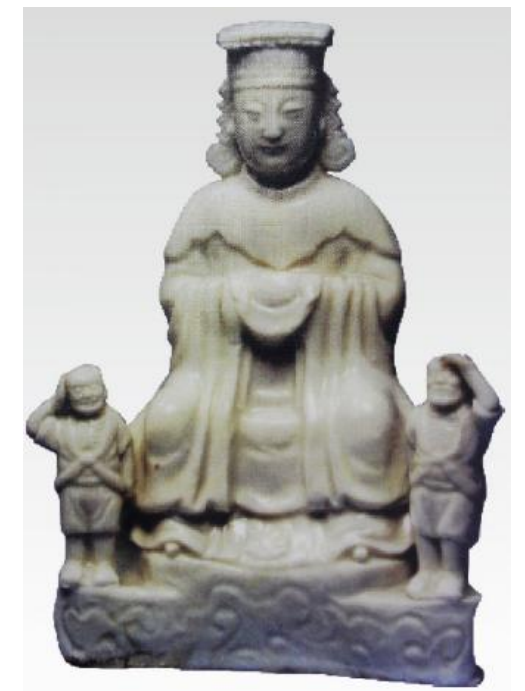

Fig. 9. Moralization porcelain carving Matsu statue of Ming Dynasty in Tang Hongie's Appreciation of Matsu Statue of Past Generations

\section{Supreme Queen of Heaven Image}

In the 23rd year of Kangxi administration(1684 AD), due to Matsu helping Shi Lang obtain great victory of Penghu, she is entitled "Benevolent queen of heaven protecting the country and people"; Matsu's godhood gets promoted to queen of the heaven from imperial concubine of the heaven. Governors of Qing Dynasty prefer magnificence and complicated decoration. In Tongzhi and Guangxu period, gorgeous and colorful "Lacquer thread sculpture" craft which is as elaborate as hairline appears in statue sculpture. It is commonly called "Yongchun work". There is a crown with nine tassels on head. She wears tarshish stripe dragon robe with one hand in the other before her chest and a jade tablet in her hand. The graceful posture image becomes the model of Matsu's supreme queen of the heaven image. Nowadays, most of Matsu status seen by people are images of Matsu as queen of the heaven in style of this period, like "Fig.10".

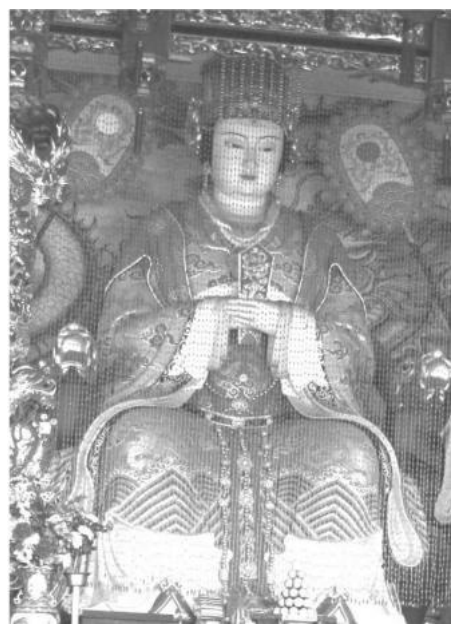

Fig. 10. Meizhou Matsu statue in Wang Yingying's Analysis on Artistry of Putian Matsu Statue Sculpture

\section{E. Diversified Development of Modern Image of Matsu}

Right now, we are in a new era of cultural and artistic innovation and constant emergence of various artistic ideological trends and artistic styles. With commercialization of economy and culture and globalization, people's aesthetic taste of image of Matsu also goes towards diversified development. Especially Matsu believers of youth generation, they grow up in cartoon stories and animax and they are unsatisfied in gorgeous, exquisite, dignified and mysterious traditional statue image of Matsu. They yearn for creativity and innovation.

Therefore, Q-version Matsu "emerges as the times require". Its biggest characteristic is to simplify complicated costume displaying hierarchy sense in traditional Matsu image; It displays cute facial expressions instead of previous dignified and serious ones; It changes proportional relation of her head and body: Normal people are about 1: 7 and Q-version Matsu is usually under $1: 5$. Some even are just as high as two heads, like "Fig. 11" and "Fig.12". Both young people and elder uncles and grandpas love and are happy to accept various Qversion Matsu toys, card stickers, pendants and other goods in life. Matsu's cute and innocent Q-version image narrows the distance between the public and gods, and embodies development direction of reformation and advancing with the times of Matsu image under current era background.

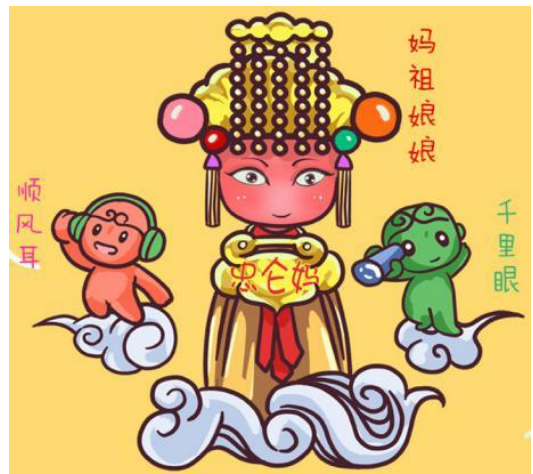

Fig. 11. Q-version Matsu image design for Xiamen God Clouds Palace provided by Cai Jianlong, Xiamen

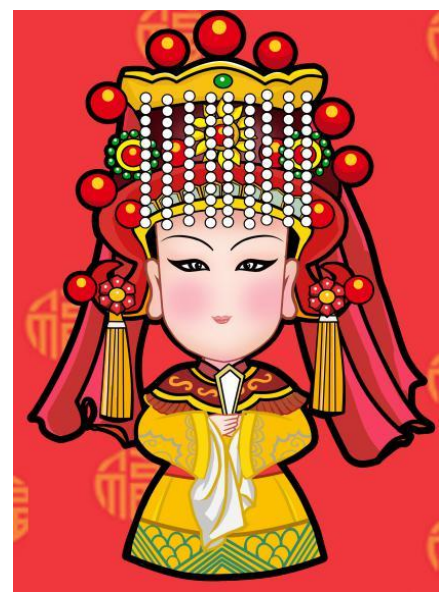

Fig. 12. Q-version Matsu image design for Chaozong Palace in Xiamen by the author 


\section{CONCLUSION}

In conclusion, this paper clears up relevant description content of Matsu's personal image in life story and legend material of Matsu, does up promotion venation of Matsu's godhood, refers to statue material corresponding to her godhood identity of various eras and combines with reformation development trend of Matsu image under current era background to find out: Due to influence of era, region, politics, economy, culture and other elements, Matsu image has characteristics of advancing with the times. Matsu belief and Matsu culture are "living belief" and "living culture" in constant development and change. Therefore, Matsu image is always the "living image" with fresh vitality. It means that not matter it is Matsu statue creation or Matsu image design of other types, they should know development history of Matsu image and combine with era background in order to create "living" Matsu image with artistic appeal.

\section{REFERENCES}

[1] Lin Qingbiao, Entitlement of Queen of the Heaven, Qing Dynasty.

[2] Lin Qingchang, Autograph of Matsu -- Annotation and Analysis on Entitlement of Queen of the Heaven, Zhongshan University Press, 2003.1.

[3] Huang Ruiguo as editor-in-chief, Outline of Matsu Study, People's Publishing House, 2013.8.

[4] Tang Hongjie, Appreciation of Matsu Statue of Past Dynasties, Oriental Collecting Sundry and Rare Curios, http://www.cnki.nct.

[5] Huang Hui, Uniform Type of Past Dynasties in China, Jiangxi Art Publisher, 2011.1.

[6] Song History: Volume 65, [M], Beijing: Zhonghua Book Company, 1977:1430.

[7] Wang Yingying, Analysis on Artistry of Putian Matsu Statue Sculpture, Jimei University Journal(Philosophy and Social Science Edition), 2011.4.

[8] Wang Yingying, Analysis on Statue Concept of Matsu Image in Fujian and Taiwan in Modern Cultural Construction, Fujian Normal University Journal(Philosophy and Social Science Edition), 2014.1. 